14 | Tropelías. Revista de Teoría de la Literatura y Literatura Comparada, 23 (2015)

Fernando Azevedo

\title{
APONTAMENTOS SOBRE A CONSTRUÇÃO CULTURAL DAS REPRESENTAÇÕES DA FAMÍLIA NA LITERATURA INFANTIL PORTUGUESA CONTEMPORÂNEA
}

\author{
Fernando AZEVEDO \\ Universidade do Minho \\ fraga@ie.uminho.pt
}

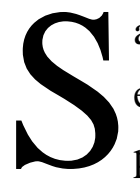

abemos que a literatura, modelizando o real, constitui um instrumento gerador de significativos efeitos perlocutivos. Os textos da literatura infantil, propondo determinados mundos e eventos, possibilitam afirmar indiretamente certos estados de coisas, contribuindo não só para a socialização dos seus leitores, como, muito frequentemente, também para a construção da sua identidade.

Um dos temas que é transversal à literatura infantil é o da família e nele se retratam papéis importantes no agir pessoal e coletivo. Kimberley Reynolds (2005: 25) assinala que a simples utilização da expressão "ser membro da família" ou "pertencer à família" acarreta a imediata conotação de que se faz parte de um determinado grupo, independentemente das eventuais relações de natureza biológica.

Tópico dominante na literatura infantil e frequentemente metonímia do Estado e de outras formas de governabilidade, na aceção em que concretiza os desejos coletivos, os sonhos e a visão política de uma potencial nova ordem social, as representações da família são consideradas como um conceito socialmente construído (Tucker \& Gamble, 2001), determinado por condicionantes várias como a classe, a cultura ou o momento histórico (Bradford, Mallan, Stephens \& McCallum, 2008: 130).

As suas representações na literatura têm-na mostrado como uma construção social simultaneamente problemática e ideal: problemática, no sentido em que jamais é apresentada como uma entidade única e definitivamente determinada; e ideal, na aceção em que as famílias comportam o essencial das promessas utópicas de um melhor futuro (Bradford, Mallan, Stephens \& McCallum, 2008: 130). De facto, numa obra consagrada ao estudo da família na literatura infantil inglesa, Ann Alston (2008: 1) assinala que ela é comummente associada a uma retórica segundo a qual a verdadeira felicidade parece ser impossível de alcançar sem o amor e o apoio de um núcleo ou grupo familiar dedicado. A família é, no fundo, apresentada como o reduto da proteção e do cuidado, o calor que garante a continuidade e a segurança, em oposição aos lugares inóspitos do mundo onde reina a 


\section{Tropelías. Revista de Teoría de la Literatura y Literatura Comparada, 23 (2015) \\ Apontamientos sobre a construção cultural das representações da família na literatura...}

insegurança e o sofrimento. Porém, o retrato que a literatura infantil faz dela continua a ser, apesar das alterações nos contextos sociais, culturais, políticos e religiosos que temos vindo a experimentar no mundo contemporâneo ${ }^{1}$, predominantemente conservador. Inclusivamente, como pertinentemente sublinha a autora (Alston, 2008: 2), «children's literature rarely asks the fundamental question of what constitutes family, and what, if anything is ideal».

Olhando para a produção editorial publicada em Portugal que tem como público-alvo as crianças, verifica-se que são ainda pouco frequentes as obras nas quais se questiona o modelo nuclear de família ou se equacionam outros modelos no âmbito dos quais as crianças podem ser socializadas e protegidas.

Se já se encontram textos que explicitamente abordam a questão do divórcio e da existência de famílias monoparentais -contribuindo, de algum modo, para desafiar determinados padrões estereotipados-, a tendência continua a ser a da recuperação de mundos de nostalgia, onde o modelo de família clássica ocupa um lugar de destaque ${ }^{2}$.

Em Um Farol só Meu (Chico, 2004), álbum de potencial receção leitora infantil recomendado pelo Plano Nacional de Leitura, e onde os desenhos, em grande plano, ocupam frequentemente a dupla página, narra-se, num registo pessoal e afetivo, o esforço e a dedicação de uma menina para a construção de um farol que possa auxiliar o pai, pescador, a regressar a casa.

Jogando graficamente com os contrastes escuridão/sombra e luz, o texto presentifica uma ausência causadora de sofrimento e o desejo expresso da criança ${ }^{3}$ :

Por muito longe que estivesse o meu papá, por muito escuro que fosse...

Não poderia deixar de ver a minha luz, o farol que eu tinha construído só para ele.

Se hoje o meu papá chegar a casa, da janela do meu quarto verá o mar, a praia, e muitos barcos de pesca... E o meu farol de amor (Chico, 2004: s/p).

Em Os Meus Pais Estão Separados, Mas Não de Mim (Taveira, 2004), O Namorado da Minha Mãe (Gonçalves, 2007) ou Os Meus Pais Separaram-se (Pato e Oliveira, 2008), o tópico dominante é a questão do divórcio, reforçando-se a necessidade de uma visão positiva, globalmente inclusiva e dialogante acerca do outro e da sua receção numa nova conceção de família, a qual, não sendo rigorosamente igual à de um certo modelo predominante, é, também ele, um espaço onde a afetividade se constrói e os laços familiares se aprofundam e germinam.

\footnotetext{
${ }^{1}$ Entre outros aspetos, assinalamos que o conceito de família parece ter-se alterado nas últimas décadas: cada vez mais as famílias enfrentam o divórcio; ao lado do modelo tradicional convivem outros modelos, como o das famílias monoparentais; a alteração das condições socioeconómicas do agregado, com ambos os pais a trabalhar fora de casa, tem introduzido mudanças na representação da mesma; as crianças parecem ter-se tornado mais centrais nas preocupações familiares; os contextos sociológicos e religiosos também se modificaram, etc. A este propósito, Jack Zipes (2002) assinala a alteração da perceção que muitos jovens possuem da noção de família, decorrente do mercado capitalista em que vivem imersos: segundo o autor, muitos jovens identificam-se mais com um grupo consumidor de determinadas marcas do que como membros que pertencem ou que fazem parte de uma família.

${ }^{2}$ Cf., por exemplo, obras como A Princesa Corajosa (Contumélias, 2006) ou Papoila, o Príncipe e o Sonho (Ferreira, 2006).

${ }^{3}$ Sara Reis da Silva (2005: 82-84), na recensão que efetua acerca desta obra, refere-se a ela como um livro «com um próposito notoriamente afectivo», onde se ficionaliza acerca de temáticas como o medo, a insegurança e a angústia da separação.
} 
Os álbuns narrativos Um Milhão de Beijinhos (Lé, 2005), Um Livro sobre a Minha Mãe (Faria, 2008) ou Coração de Mãe (Martins, 2008) explicitam as vivências afetivas que unem os protagonistas em contextos familiares monoparentais.

No primeiro fala-se do amor de uma filha pelo seu pai e realça-se a importância dos pequenos gestos para a construção coletiva da felicidade. Evidenciando uma nítida diferença entre o olhar da criança e o olhar do adulto face ao mundo empírico e histórico-factual, também aqui, à semelhança do que ocorre em $O$ Principezinho, de Saint-Exupéry, se mostra que o essencial é invisível aos olhos.

O álbum de Ana Faria (2008) apresenta o ponto de vista afetivo de uma menina face à sua mãe: as suas conversas, os seus passeios, o seu quotidiano e a convicção que é nela que sempre encontrará as palavras amigas quando tal se revelar necessário.

Em Coração de Mãe (Martins, 2008), álbum que obedece a uma construção dicotómica, explicase a profunda relação afetiva e umbilical que une o coração de uma mãe ao seu filho.

A Minha Mãe é a Melhor do Mundo (Carvalho, 2005) constitui um humorístico texto onde se relata a relação de um filho com a sua mãe. Desgostoso da mãe que tem, Gil, uma criança de cinco quase seis anos, decide ir à Loja das Mães e trocá-la por uma outra, mais adequada aos seus desejos e necessidades. Porém, depois de uma série de contratempos, a criança chega à conclusão que a mãe, tal como se apresenta, é, de facto, a melhor do mundo e insubstituível.

A conceção do núcleo familiar integrando os avós é abordada, por exemplo, em obras como $A$ Avó, de Peter Härtling (1988), O Meu Avô, de Manuela Bacelar (1990), Um Avô Inesquecível, de Bette Westera (2005), A Avó e a Escola, de Odete Praça (2009), Quando Eu Nasci, de Isabel Minhós Martins (2007) ou As Duas Estradas (Martins, 2009).

Se, na obra de Peter Härtling (1988), o pequeno Kalle, em virtude de ter ficado órfão, vai viver com a avó paterna -e, neste contexto, o leitor tem a oportunidade de experimentar a relação afetiva entre os mais novos e os mais velhos-, no álbum narrativo $O \mathrm{Meu} A v o ́$ retratam-se, com «uma sensível tonalidade risonha» (Silva, 2005: 66), as peripécias do quotidiano que perduram entre membros de uma família durante uma vida e gerações diferentes. Ambos os textos enfatizam os laços de afetividade que unem as duas gerações, não deixando de sublinhar as diferenças entre elas.

No álbum narrativo Um Avô Inesquecível (Westera, 2005), obra recomendada pelo Plano Nacional de Leitura, recorda-se, com emoção, a figura carinhosa, próxima e inesquecível do avô. A narrativa inicia-se no dia do seu funeral, poucos momentos antes do caixão baixar à terra. João, o neto, recorda, com lágrimas nos olhos, um conjunto de episódios marcantes na sua ainda curta vida: as brincadeiras («Ele era um cowboy na pradaria e o avô era o cavalo», a construção de um barco de piratas, o divertimento na praia), o espírito de aventura e de cumplicidade, a iniciação tutelada pelo avô (o aprender a andar de bicicleta), e toda uma série de pequenos gestos partilhados, onde sobressaem as diferenças entre os seus mundos e o mundo dos outros adultos: correr...

João não sabia que os crescidos podiam andar tão devagar. Nas ruas da sua cidade andavam sempre a

Olha para o caixão onde está o avô.

Há tantas coisas que gostaria de lhe perguntar: 
Apontamientos sobre a construção cultural das representações da família na literatura...

Se está escuro dentro do caixão.

Se morrer dói.

Se o avô está no céu, como diz a tia Luísa.

E como é o céu.

Mas o tio Jorge diz que o céu não existe.

Quem é que está certo, avô?

Lentamente, o caixão é descido para a cova.

Os crescidos atiram mãos-cheias de terra para a cova.

-Eu não quero, -diz João, escondendo-se atrás da mãe (Westera, 2005: s/p).

Também a obra A Avó e a Escola (Praça, 2009) se centra na relação afetiva e de partilha de saberes entre uma avó e o seu neto. Num conjunto de quadras rimadas, a avó inicia o seu neto no conhecimento do mundo, abordando aspetos vários como a alimentação, a higiene, a ciência, a sexualidade ou a história.

Num discurso em $1^{\text {a }}$ pessoa, o álbum Quando Eu Nasci (Martins, 2007) relata as emoções e as primeiras experiências do olhar de uma criança face ao mundo e, nesse contexto, refere-se explicitamente o prazer sentido pelo «cheiro do colo da minha avó.»

Em As Duas Estradas (Martins, 2009), álbum narrativo que propõe dois percursos de leitura diferentes, narra-se, num registo pessoal e entrecortado de observações, uma viagem de carro de um menino, acompanhado do pai e da avó, para visitar a família. Invertendo o livro, o álbum propõe-nos uma outra viagem com outros protagonistas: partindo da cidade, o percurso leva-nos, num mesmo registo pessoal e afetivo, até ao ambiente rural, um espaço dominado por outro tempo e por outra sinalética. Mesmo não o explicitando, ambos os percursos entrecruzam-se e parecem finalizar no mesmo lugar: o do encontro da família.

Uma obra fortemente marcante na questão das representações da família e dos lugares atribuídos aos seus vários membros, e que aliás é recomendada pelo Plano Nacional de Leitura, é O Livro dos Porquinhos, de Anthony Browne (2006).

A capa anuncia o fundamental da ação e configura-se como um grito de denúncia: se o título é, por si, causador de algum estranhamento (Serafini, 2010: 93), a imagem inusitada de uma certa representação familiar (a mulher sem expressão, presumivelmente a mãe, carregando às costas dois rapazes, vestidos com uniforme escolar, e um homem de fato, presumivelmente o pai, todos eles sorridentes), configura um horizonte de expectativas eventualmente dominado por uma série de questões. Por que razão a mãe carrega um homem adulto e duas crianças às costas? Que relação é possível estabelecer entre a ilustração e o título? Que relações existem nesta família? Será que se trata mesmo de uma família?

A contracapa mostra um bilhete manuscrito, que um ser animal segura, e onde se pode ler uma acusação violenta: «Vocês são uns porcos.»

Neste álbum de potencial receção leitora infantil, narra-se, muito à custa de um curioso e interessante jogo cromático, o quotidiano de uma família de classe média, composta por dois adultos e duas crianças, sendo que à mãe, para além da sua profissão, se encontravam atribuídas, com exclusividade, todas as tarefas domésticas. A razão de tão singular situação é dada pelo texto verbal: todos os elementos do sexo masculino desempenham tarefas «importantíssimas», seja no trabalho seja 
na escola, e não se coíbem de dar ordens à Sra. Porcino para que melhore os seus índices de produtividade.

A visão patriarcal do mundo e o consequente afastamento da mulher para a periferia das atividades sociais são aspetos dominantes nesta obra (Bradford, 1998: 88).

Se os elementos do sexo masculino são retratados numa pose ora de descanso ora de fruição alimentar (todos sentados à mesa, a comer), a mãe, a quem nunca se consegue visualizar o rosto, é mostrada nas suas lides domésticas, aspeto reforçado pelo texto verbal:

\footnotetext{
Depois de todos saírem de casa, a Sra. Porcino lavava a loiça do pequeno-almoço... fazia as camas... aspirava o chão... e depois ia para o trabalho.

[...] Assim que todos acabavam de lanchar, a Sra. Porcino lavava a loiça... lavava a roupa... passava a ferro... e depois voltava a cozinhar (Browne, 2006: s/p).
}

A narrativa desenvolve-se num crescendo até que, um dia, quando o marido e os filhos regressam a casa, se deparam com a ausência da mãe. É partir desse momento que se opera uma metamorfose nas personagens e todas elas vão adquirindo progressivamente semas de animalidade.

Jogando com conhecidas referências intertextuais da narrativa Os Três Porquinhos, a família, agora restrita ao pai e aos seus dois filhos, dá-se a ler como progressivamente vulnerável e desestruturada, ao ponto de todo o quotidiano ser profundamente afetado.

Ao pedido para que regresse a casa, segue-se a alteração dos comportamentos ${ }^{4}$, com a repartição, entre todos, das tarefas domésticas e, pela primeira vez, o leitor pode ver as feições do rosto da mãe e reconhecer a sua felicidade.

Esta é, pois, uma obra que, na linha de outras como A Família $C$, de Pep Bruno \& Mariona Cabassa $(2010)^{5}$, denuncia determinados estereótipos de género, possibilitando uma leitura crítica à luz de uma pluralidade de contextos sociais, culturais e ideológicos.

O panorama editorial português deparou-se no ano de 2008 com duas obras que, vocacionadas para a infância, retratam outros modelos de famílias. Referimo-nos a $O$ Livro do Pedro (Maria dos 7 aos 8), da ilustradora e escritora Manuela Bacelar (2008), e Ser Diferente é Bom, de Sónia Pessoa (2008).

O nascimento próximo de uma criança, filha de Maria, é o mote que dá azo a $O$ Livro do Pedro (Maria dos 7 aos 8). Trata-se de uma obra que, construída numa estrutura de myse-en-abîme, narra, num registo autobiográfico, a infância de uma criança, num período em que vive com os seus dois pais: Pedro e Paulo. Tal como qualquer criança dessa faixa etária, também Maria convive regularmente com os seus primos, em casa da sua avó, estuda numa escola onde, para além da professora, tem muitos

\footnotetext{
${ }^{4}$ Clare Bradford (1998), num artigo consagrado à representação da masculinidade nas obras de Anthony Browne, refere a natureza fortemente irónica deste texto onde a conjugação dos textos verbal e gráfico contestariam a possibilidade da igualdade no que respeita aos papéis sociais e domésticos.

${ }^{5}$ Vencedora do III Prémio Internacional Compostela para álbuns ilustrados, nesta obra é a mãe quem lê o jornal enquanto o pai prepara o pequeno-almoço. Contrariando determinados estereótipos de género, a mãe trabalha num hospital e o pai é alfaiate. A harmonia familiar e o ambiente de festa e alegria, anunciado pela ida coletiva ao circo, no final da narrativa, são uma constante, reforçada pelo texto gráfico que ocupa todas as páginas.
} 
amigos, recebe-os em sua casa, vive o dia-a-dia familiar, com toda a naturalidade, carinho e profunda afeição por parte dos seus pais adotivos, Pedro e Paulo.

Agora que cresceu, e vai ser novamente mãe, Maria conta à sua filha a história da sua vida e, uma vez nascido o irmão, será a filha que irá, por sua vez, contar ao irmão esta meta-narrativa em que a protagonista foi a sua mãe.

A nível gráfico, são detetáveis na obra dois momentos distintos: num primeiro, um estilo a lápis, de contornos suaves e com um fundo pérola -momento em que Maria adulta e grávida relembra, com nostalgia, o período da infância e o reconta à sua filha- e, num segundo, um estilo com contornos a tinta, cores garridas e tramas mais fortes - momento em que Maria revive, com exuberância, a alegria, a espontaneidade e a felicidade da sua infância-.

No fundo, esta é uma obra que, tal como é referido na sinopse, que acompanha o catálogo editorial, contempla, com naturalidade, a diversidade das formas de parentalidade: o retrato que aqui é feito de Maria é o de uma criança semelhante a outras, que vive a sua infância feliz e integrada numa comunidade.

A diversidade do modelo parental, a que se associa a questão do multiculturalismo, é igualmente o tema da obra Ser Diferente é Bom (Pessoa, 2008).

Pedro e Maria são duas crianças que, com famílias diferentes, mas vivências semelhantes, se reencontram no primeiro dia de aulas depois das férias e, nesse contexto, fazem novos amigos, particularmente Ion, um menino proveniente da Roménia. A narrativa, estruturada por episódios, mostra-nos o quotidiano das crianças em contexto familiar e escolar, um quotidiano no âmbito do qual elas partilham com os pais as suas vivências e descobertas.

No fundo, esta é uma obra que também apresenta dois modelos diferentes de parentalidade, assumindo-os como não detentores de qualquer marca de alteridade, sob o ponto de vista simbólico. Trata-se, com efeito, como sublinha a informação peritextual, de autoria de uma psicóloga, de estimular um convívio com as diferenças e de suscitar e fomentar o diálogo entre todos.

O conjunto de textos que aqui apresentámos e que mais não são que um mero estudo exploratório desta temática, mostram-nos, no seu conjunto, que, apesar de organizações diversificadas do núcleo familiar, a literatura infantil publicada em Portugal continua a postular, sob o ponto de vista ideológico, os seguintes princípios:

- A importância da família para a garantia da segurança emocional das crianças;

- A importância da família para o desenvolvimento de cidadãos responsáveis, tolerantes e solidários;

- A importância da família para o crescimento e posterior autonomia do sujeito. 


\section{Referências bibliográficas:}

Alston, A. (2008): The Family in English Children's Literature. New York and London, Routledge. BACERLAR, M. (1990): O Meu Avô. Porto, Edições Afrontamento. (2008): O Livro do Pedro (Maria dos 7 aos 8 Anos). Porto, Edições Afrontamento.

Bradford, C. - Mallan, K. - Stephens, J. - McCallum, R. (2008): New World Orders in Contemporary Children's Literature. Utopian Transformations. New York, Palgrave Macmillan.

BRADFORD, C. (1998): «Playing with Father: Anthony Browne's Picture Books and the Masculine», Children's Literature in Education, 29/2, pp.79-96.

Browne, A. (2006): O Livro dos Porquinhos. Lisboa, Kalandraka Editora. [Ed. Original (1986): Piggybook. Walker Books]

Bruno, P. - CABassa, M. (2010): A Família C. Matosinhos, Kalandraka Editora Portugal.

Carvalho, M. J. L. (2005): A Minha Mãe é a Melhor do Mundo. Ilustrações de Helena Nogueira. Cruz Quebrada, Oficina do Livro.

ChICo (2004): Um Farol só Meu. Porto, Âmbar.

Contumélias, M. (2006): A Princesa Corajosa. Lisboa, Plátano Editora.

FARIA, A. (2008): Um Livro sobre a Minha Mãe. Lisboa, Livros Horizonte.

Ferreira, S. R. (2006): Papoila, o Príncipe e o Sonho. Ilustrações de E. Pereira. Porto, Papiro Editora. GonÇALVES, V. (2007): O Namorado da Minha Mãe. Ilustrações de J. Tinoco. Lisboa, Gradiva Júnior. HÄRTLIng, P. (1988): A Avó. Ilustrações de Ingrid Mizsenko. Tradução e adaptação de Ana Losa Ramalho. Porto, Edições Afrontamento.

LÉ, E. (2005): Um Milhão de Beijinhos. Porto, Ambar.

Martins, I. M. (2007): Quando Eu Nasci. Ilustrações de Madalena Matoso. Oeiras, Planeta Tangerina. - (2008): Coração de Mãe. Ilustrações de B. Carvalho. Oeiras, Planeta Tangerina.

- (2009): As Duas Estradas. Ilustrações de Bernardo Carvalho. Oeiras, Planeta Tangerina. Pato, P. - Oliveira, P. (2008): Os Meus Pais Separaram-se. Algueirão Mem-Martins, K Editora. PessoA, S. (2008): Ser Diferente é Bom. Ilustrações de Carla Carvalho. Lisboa, Papiro Editora. PRAÇA, O. (2009): A Avó e a Escola. Ilustrações de Abigail Ascenso. Porto, Areal Editores.

REYNOLDS, K. (Ed.) (2005): Modern Children's Literature. An Introduction. New York, Palgrave Macmillan.

SERAFINI, F. (2010): «Reading Multimodal Texts: Perceptual, Structural and Ideological Perspectives», Children's Literature in Education, 41, pp. 85-104.

Silva, S. R. (2005): Dez Réis de Gente... e de Livros. Notas sobre Literatura Infantil. Lisboa, Caminho.

TaveIRA, I. B. (2004): Os Meus Pais Estão Separados, Mas Não de Mim. Ilustrações de F. Fragateiro. Porto, Campo das Letras.

Tucker, N. - Gamble, N. (2001): Family Fictions. London, Continuum. 

Apontamientos sobre a construção cultural das representações da família na literatura...

WesterA, B. (2005): Um Avô Inesquecível. Ilustrações de Harmen van Straaten. Lisboa, Livros Horizonte.

ZIPES, J. (2002): Sticks and Stones. The Troublesome Success of Children's Literature from Slovenly Peter to Harry Potter. New York \& London, Routledge. 